\title{
Estimation of the Appropriate Output of Diesel Generator for Microgrid System in Chuja Island
}

\author{
Seungmin Lee ${ }^{1}$, Sang Heon Chae ${ }^{2}$, Eel-Hwan Kim ${ }^{2 a}$, Ho Min Kim ${ }^{1}$ and Ngoc-Thinh Quach ${ }^{2}$ \\ ${ }^{1}$ Faculty of Wind Energy Engineering Graduate School, Jeju National University, S. Korea \\ ${ }^{2}$ Deparetment of Electrical Engineering, Jeju National University, S. Korea
}

\begin{abstract}
This paper proposes a method to estimate the appropriate minimum output of diesel generator in the microgrid system that composed of renewable energy, diesel generator and energy storage systems. While maximizing the output of the renewable energy in the microgrid, to maintain the power system stability is very important. To analyze the effectiveness of the proposed method, simulation is carried out by using the PSCAD/EMTDC program with past weather and power load data in Chuja Island located in the south area of Korean peninsula, respectively. In the simulation result, power quality of Chuja Island power system under variable renewable energy generation is stable. The proposed method is useful for operating the isolated microgrid system.
\end{abstract}

\section{Introduction}

In order to solve the energy supplying problem for isolated area, the use of microgrid has been promoted all over the world. The microgrid is an integration of wind turbine, photovoltaic (PV), energy storage system (ESS) and diesel generator [1]. The most important objectives of microgrid are minimization of operating diesel generator and grid stability [2]. Therefore the microgrid must be designed to meet these conditions. There are two types of microgrid. One is on-grid type of microgrid, which is connected to main grid. This microgrid is operated by renewable energy sources and conventional source from main grid. In this case, if the load of microgrid is higher than renewable energy sources, the microgrid will receive the demand power from main grid. If the load of microgrid is lower than renewable energy sources, the microgrid will transmit the redundant power to main grid [3]. Another is off-grid type of microgrid, which is isolated system and always operates stand-alone. Because this microgrid cannot share electric power with main grid, the diesel generator can be supported for grid stability by sustaining minimum operation. Therefore elaborate energy management system is essential to this microgrid. Recently, the government of South Korea has a plan named 'Green and energy self-reliance Island', the objective of the plan is to make off-grid type microgrid for isolated islands by using non-pollution energy. In South Korea, two islands named Gapa and Gasa were already installed to off-grid microgrid from this plan [4]. Jeju Special Self-governing Province will make another microgrid system in Chuja Island by 2019. From this point, this paper proposes the estimating method of

\footnotetext{
a Corresponding author: ehkim@jejunu.ac.kr
}

operation range for diesel generator focused on Chuja Island to minimize air pollution and grid stability. The operation of microgrid system in Chuja Island will be verified by using PSCAD/EMTDC simulation program. PV and wind turbines output power will be calculated by using matlab program.

\section{Overview of microgrid system in Chuja Island}

Chuja Island is located in the north of Jeju Island in South Korea. Presently, the power grid on this island is only operated by seven diesel generators with the total capacity of $5.5 \mathrm{MW}$. However, the government has a plan to install microgrid system in Chuja Island by 2019 as illustrated in Fig. 1. In this plan, the capacity of components for microgrid system in Chuja Island is already determined. The components of Chuja Island microgrid consist of PV system with the total capacity of 1.6 MW, ESS with the total capacity of $12 \mathrm{MWh}$, wind turbines with the total capacity of $2.4 \mathrm{MW}$. The demand load of this island is estimated about $1.24-2.74 \mathrm{MW}$.

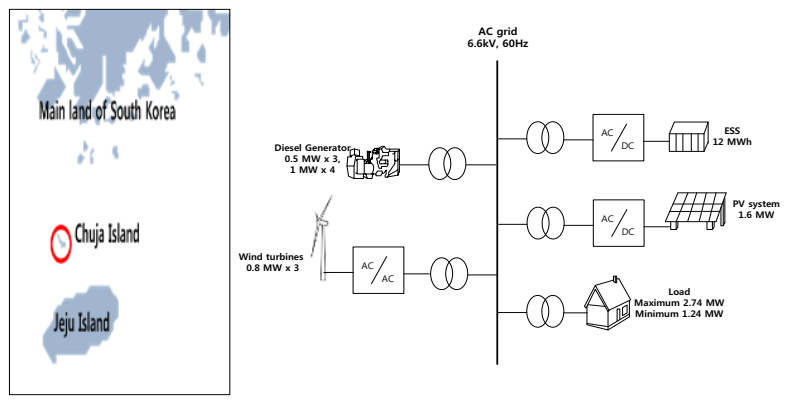

Figure 1. Configuration plan of microgrid system in Chuja Island 


\section{Modeling of microgrid system in Chuja Island}

The microgrid system in Chuja Island is designed by PSCAD/EMTDC simulation program [5]. Line impedances of Chuja Island distribution grid will be applied by actual line model. The actual parameters of transformer are also considered for simulation. The distribution voltage for microgrid system in Chuja Island is $6.6 \mathrm{kV}$.

\subsection{Energy storage system}

In order to simulate proposed method, the ESS is modelled by shepherd nonlinear battery model referred to SAFT's model as shown in Fig. 2. The capacity of a basic lithium ion battery is $5.4 \mathrm{Ah}$ and the nominal voltage is $4.2 \mathrm{~V}$. Through series and parallel connection of the batteries, its capacity and system nominal voltage is calculated. The state of charge (SOC) of ESS is set from 0.2 to 0.8 . Power conversion system (PCS) of ESS plays a role as a DC/AC inverter. The PCS is made from two level voltage source inverter. In this study, it will control for active power and reactive power based on current controller as illustrated in Fig. 3 [6].

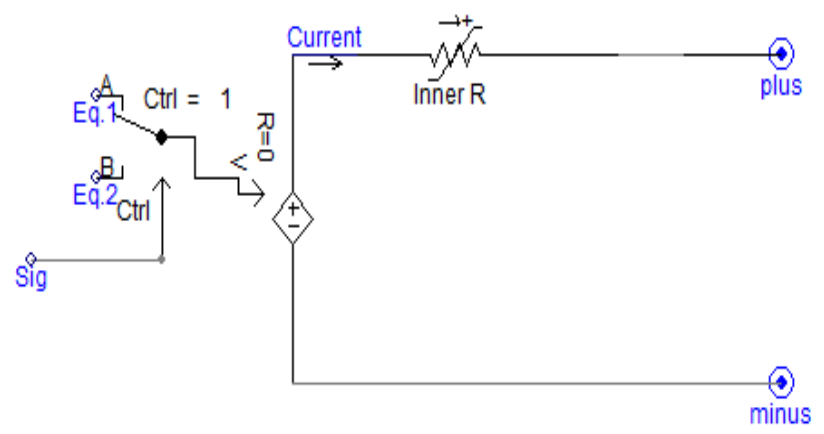

Figure 2. Battery equicalent model in PSCAD/EMTDC

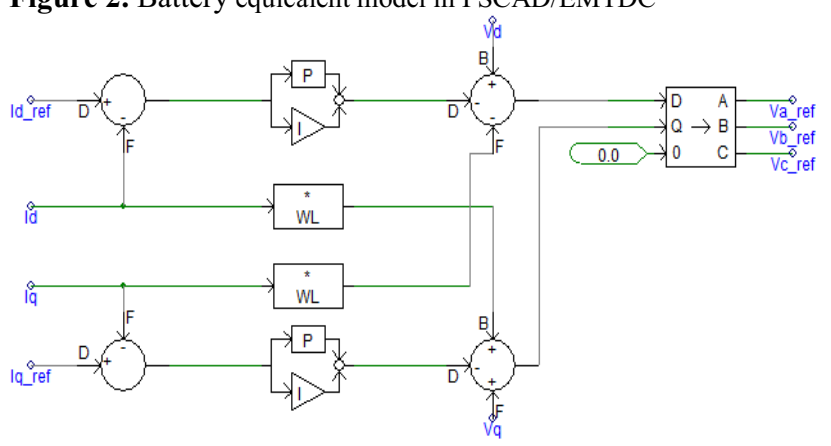

Figure 3. Schematic diagram of controlled current source in PSCAD/EMTDC

\subsection{Wind turbine}

The wind turbine is designed by controlled current source based on ENERCON's model with the each capacity of $0.8 \mathrm{MW}$ as shown in Fig. 4. The generation power of wind turbine will be calculated from its power curve by actual wind speed data on Chuja Island. From this process, the input data of controlled current source in PSCAD/EMTDC will be gotten in advance by matlab program.

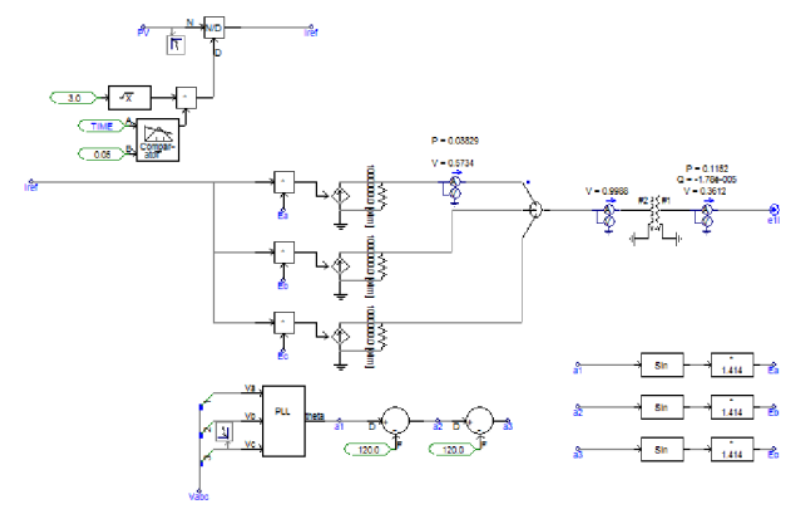

Figure 4. Equivalent current source model in PSCAD/EMTDC

\subsection{PV system}

The PV system is made from controlled current source similar with wind turbine simulation model [7]. Since it is based on DC source, its equivalent model will only generate active power. The generation power data of PV will be calculated from actual radiation data on Jeju Island nearby Chuja Island by matlab program. Gradient of PV panel is assumed at 30 degrees.

\subsection{Diesel generator}

The diesel generator is modelled from PSCAD/EMTDC library model as shown in Fig. 5. It uses actual parameter of thermal plant in Chuja Island. There are two type of diesel generator in Chuja Island. One is $0.5 \mathrm{MW}$. Another is $1 \mathrm{MW}$. The diesel generators consist of diesel engines and generators.

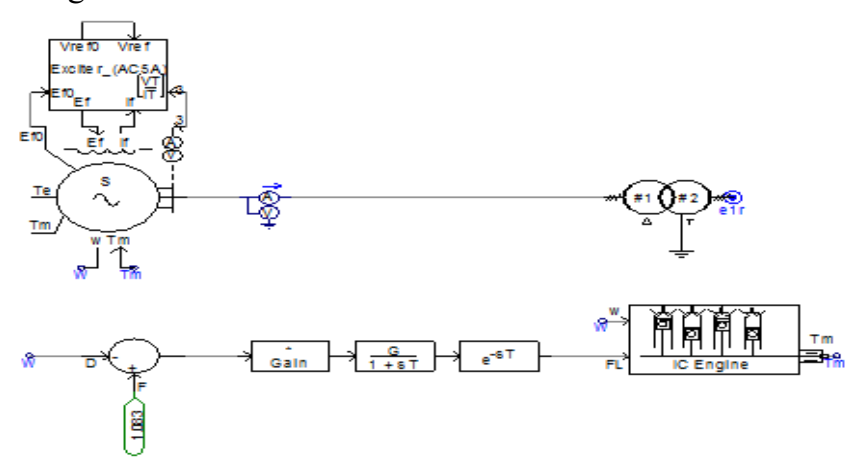

Figure 5. Diesel generator model in PSCAD/EMTDC

\section{Estimation of appropriate output of diesel generator}

Generally, one of the important points of microgrid is operation of diesel generator. It can support to the stability of microgrid more than any other sources because the diesel generator has the biggest moment of inertia. It also has robust characteristics for fluctuation of frequency and voltage. Although the diesel generator has many advantages for stability of microgrid, but the microgrid must operate with minimum diesel generator capacity in order to minimize air pollution from using fossil fuel.

Thus, this paper proposes the method of estimating 
appropriate output for diesel generator applied to microgrid for one day. This method is based on calculating renewable energy and consumption on demand load. The appropriate output for diesel generators will be calculated by using actual data of wind speed and solar radiation. Consequently, the wind and solar powers are calculated in advance. The diesel generation will be estimated in accordance with average load and renewable energy sources at specific date on Chuja Island.

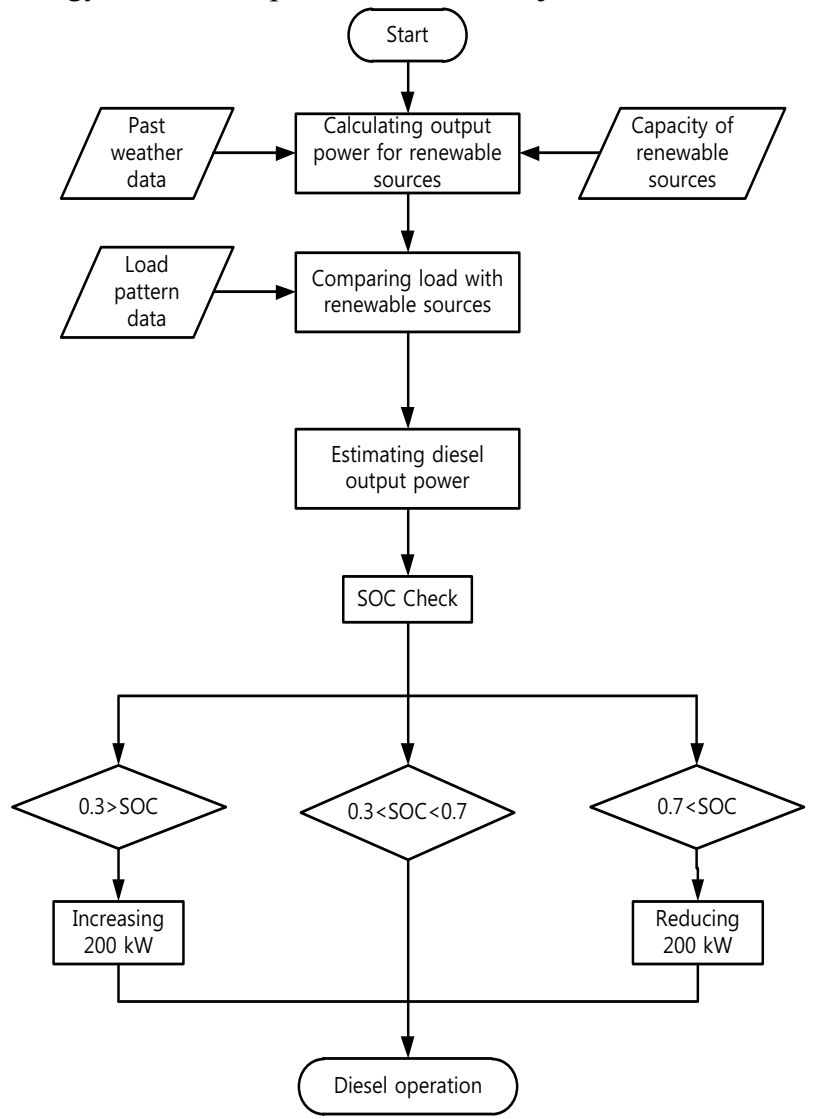

Figure 6. Flow chart of estimation for diesel generator output power

Because there is no radiation measuring device on Chuja Island, the solar radiation data on Jeju Island will be used for calculating the PV power on Chuja Island. The ESS plays a role as power balancing controller on grid. Fig. 6 shows a calculation process of appropriate output for diesel generator. In order to achieve a reliability, the past weather data at Dec. 13, 2015 will be used for calculating diesel appropriate output, because that date has highest fluctuation of output wind power in 2015. The appropriate output of the diesel generator is calculated as follows.

$$
A_{D G}=A_{R E S}-A_{D L}
$$

where, $A_{D G}$ : Diesel generation $[\mathrm{kWh}]$

$$
A_{R E S}: \text { Renewable energy [kWh] }
$$$$
A_{D L} \text { : Power consumption }[\mathrm{kWh}]
$$

Although the appropriate output of diesel generator will be calculated from renewable energy sources, it can be changed according to the SOC of ESS. The output power of diesel generator will depend on SOC of ESS because renewable energy sources have high intermittent characteristic and ESS capacity is limited. In this case, ESS will adjust the power balance between generation power and demand load. Therefore, it is essential to maintain the operation range of SOC. If the SOC is lower than 0.3 , the diesel output must be increased to $200 \mathrm{~kW}$. If the SOC is higher than 0.7 , the diesel output must be decreased to $200 \mathrm{~kW}$.

Table 1. Calculation results of microgrid on Chuja island at Dec. 13.

\begin{tabular}{|c|c|}
\hline Item & Result \\
\hline Load & $2,477,565 \mathrm{kWh}$ \\
\hline Wind Turbine & $1,319,417 \mathrm{kWh}$ \\
\hline PV System & $185,511 \mathrm{kWh}$ \\
\hline Diesel Generator & $972,636 \mathrm{kWh}$ \\
\hline $\begin{array}{c}\text { Operation Capacity } \\
\text { of Diesel Generation }\end{array}$ & $648 \mathrm{~kW}$ \\
\hline
\end{tabular}

Table 1 shows the calculating results. From this point, the renewable energy sources and demand load are calculated for power demand per one day. The output power of diesel generator is estimated. Therefore, the diesel generator will be operated with a constant power of $648 \mathrm{~kW}$. (u) for vectors. The order for brackets should be $\{[()]\}$, except where brackets have special significance.

\section{Simulation results}

The Fig. 7 shows the active power of microgrid system in Chuja Island. The ESS, PV and wind turbines are operating to response to the demand load. The diesel generator maintains the appropriate output as base generation for high stability of grid and reduction of $\mathrm{CO} 2$. In the duration time of 0:00 - 6:00, the output power of wind turbine is stable. The PV output power is almost zero. However, renewable energy sources increase in the duration time of 7:30 - 12:00. Therefore, the ESS charges for the demand load comparing with distributed resources. In duration time of 19:00 - 23:00, the output power fluctuation of wind turbine is highest. However the ESS charges power of wind turbine for grid stability.

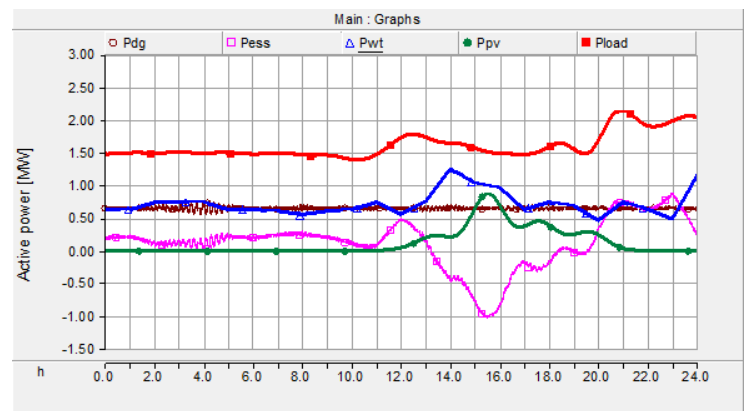

Figure 7. Active power of microgrid system in Chuja Island

The frequency of microgrid system in Chuja Island is illustrated in Fig. 8. The maximum frequency of this microgrid is $60.14 \mathrm{~Hz}$, the minimum one is $59.89 \mathrm{~Hz}$. It means that this microgrid system is achieved the 
frequency standard of South Korean government for 59.8 - $60.2 \mathrm{~Hz}$ [8]. Although the fluctuations of renewable energy sources are very high in the duration time of 07:00 - 17:00 and 19:00 - 23:00, the grid frequency maintain in stable state. The grid voltage of Chuja Island is seen in Fig. 9. The maximum voltage of this microgrid is 6.66 $\mathrm{kV}$, the minimum one is $6.57 \mathrm{kV}$. The operation of this microgrid system is achieved the voltage standard of South Korean government for 6.0 - $6.9 \mathrm{kV}$ [8]. The grid voltage stays in stable range.

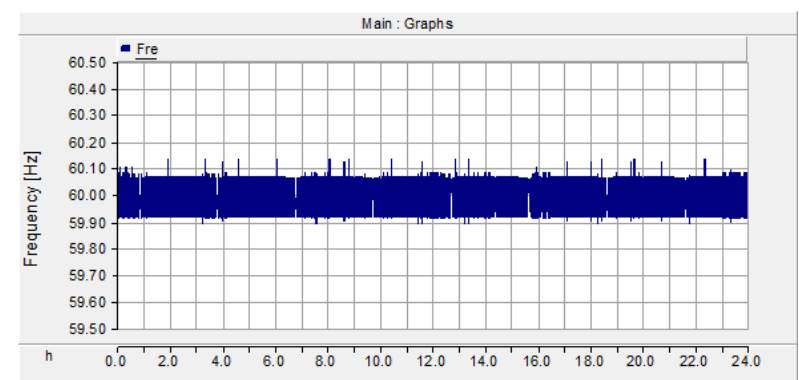

Figure 8. Frequency of microgrid system in Chuja Island

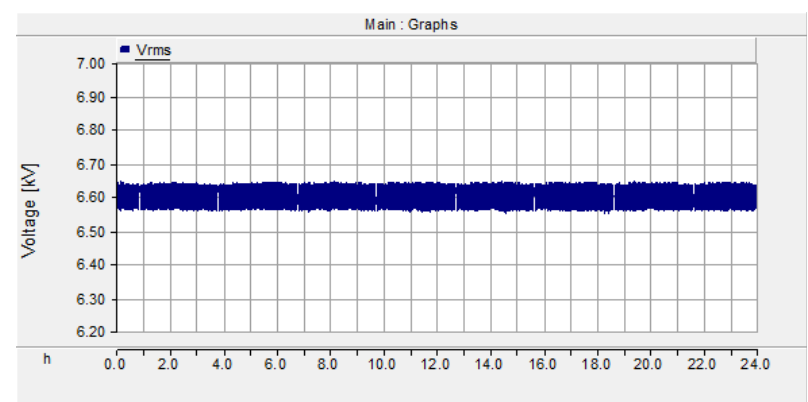

Figure 9. Grid voltage of microgrid system in Chuja Island

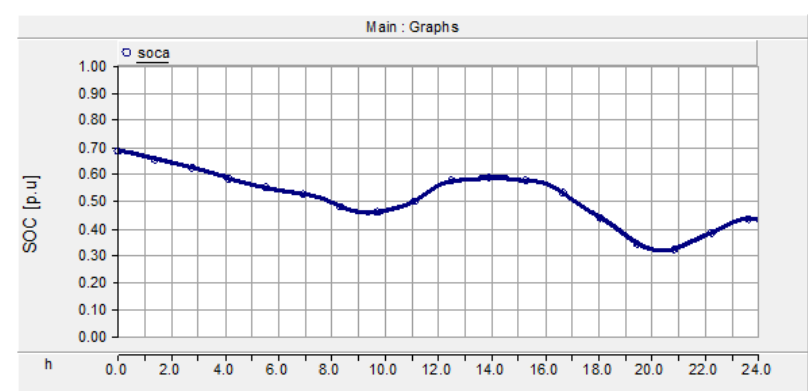

Figure 10. SOC of ESS in microgrid system in Chuja Island

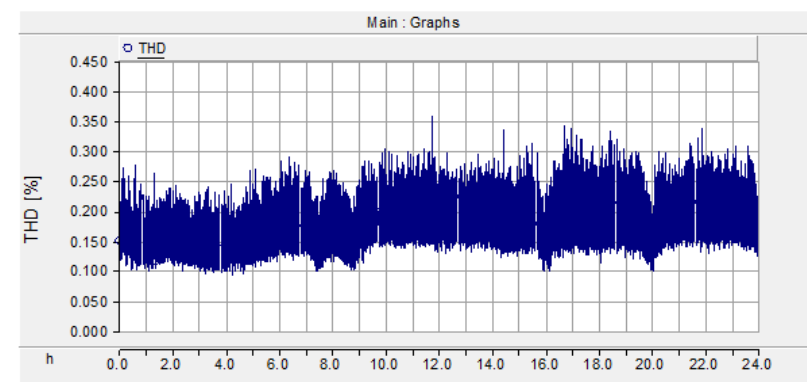

Figure 11. Total harmonics distortion of microgrid system in Chuja Island

The SOC of ESS on Chuja Island is shown in Fig. 10. In this study, The ESS operates in range of SOC from 0.2 to 0.8 .
When the load is higher than the generation power, the ESS discharges the power for the demand load. Thus, the SOC is decreased. It is also increased in contrary case.

The voltage total harmonics distortion (VTHD) of this microgrid is shown in Fig. 11. the VTHD is lower than $0.5 \%$. It means that the power quality is achieved the VTHD standard of South Korean government for 5\%.

\section{Conclusion}

This paper proposes the method for estimating appropriate output of diesel generator in microgrid system in Chuja Island. With the proposed method, the microgrid system in Chuja Island can operate stably as the demand load. Although the renewable energy sources are variable, grid voltage and frequency are also stable and achieve the standard of Korean government. The VTHD is recorded less than $0.5 \%$. It means that reliability of this microgrid system is quite reasonable in spite of inverter systems operation. The calculation result shows that the diesel generator operates at a constant power. Then, the ESS operates with range of SOC from 0.2 to 0.8 as setting point. In the future, by using the weather forecasting data, this method will be useful to estimate appropriate output of diesel generation in microgrids.

\section{Acknowledgement}

This work was supported by Graduate School of Specialized Wind Energy the Human Resources Development (NO. 20094020200020) and the Expansion of the Type Testing Site for Wind Turbines (NO. 2012T100201731) of the Korea Institute of Energy Technology Evaluation and Planning (KETEP) grant funded by Korea government Ministry of Trade, Industry and Energy.

\section{References}

1. CERT, Intergration of Distributed Energy Resource: the CERT Microgrid Concept, LBNL-50829, (2003).

2. Lasseter, T. H., Microgrids, IEEE Power Engineering Society Winter Meeting, pp. 146-149, (2001).

3. Seong Man Kim, Examples and Applications for Techniques of Microgrid, Jounal of the Electric World/Monthly Magazine Special, no. 4, pp. 37-44, (2014).

4. Policy Report, Carbon Free Island Jeju by 2030, Jeju Special Self-Gorvorning Province, May (2015).

5. Seung-Mo Song, Seung-Jin Oh, Jong-Hak Lee, JaeMin Ahn, Kyung-Min Jin, Byung-Gi Kwon, ChangHo Choi, POSCO ICT., The Application and Verificaion of the 2 MVA BESS with Wind farm in Microgrid of Gapa, Jeju, KIPE, 19, no. 4, pp. 303311, (2014).

6. KERI, Development and Experiment Actual Site of Isolated Microgrid (2010101040050A), Report. 
7. Dong-Wan Kim, A Study on the Improvement Scheme of Distributed Generation Facilites in Gapa Island Power Grid., Master Thesis, Jeju National University, (2014).

8. KEPCO, Standards of Transmission and Distribution. 